\title{
The context for reinforcement: Modulation of the response-reinforcer relation by concurrently available extraneous reinforcement
}

\author{
K. GEOFFREY WHITE \\ University of Otago, Dunedin, New Zealand \\ ANTHONY P. MCLEAN \\ Justice Department, Christchurch, New Zealand \\ and \\ MATTHEW F. ALDISS \\ Victoria University, Wellington, New Zealand
}

\begin{abstract}
Right-lever presses by hooded rats in three groups produced reinforcers at variable-intervals that differed over five conditions. The groups differed by virtue of the constant rates of reinforcers obtained by left-lever responding-high, medium, or low. The function relating right-response rates to right-reinforcer rates was adequately described by the hyperbola proposed by Herrnstein. According to Herrnstein's interpretation, the rate-of-change parameter $\left(\boldsymbol{R}_{\mathrm{o}}\right)$ for the hyperbola represents the rate of reinforcers obtained from sources other than right-lever reinforcers. Esti-

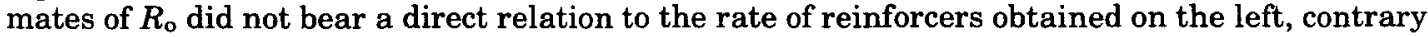
to what was expected according to Herrnstein's interpretation. There were many instances in which $R_{\mathrm{o}}$ estimates were smaller than the rate of left-lever reinforcers actually obtained. Such instances could not be accounted for by Herrnstein's hyperbola unless the undermatching and bias that were found for the choice between right and left reinforcers were taken into account. We concluded that Herrnstein's proposal that response rate can be predicted in terms of the choice between reinforcers arranged by the experimenter and reinforcers obtained from extraneous sources remains tenable if undermatching and bias are taken into account.
\end{abstract}

A dominant theme in contemporary research on operant behavior is that response strength depends on the context for reinforcement. In Herrnstein's $(1970,1974)$ influential formulation, the reinforcement context for any given behavior is specified by the outcomes of potential choices available to the individual. Herrnstein suggested that in any situation in which the relation between an operant response and its reinforcing consequences is being studied, there always exists some other behavior that is maintained by reinforcers extraneous to the experimentally defined source of reinforcers. In other words, the individual always has a choice between engaging in operant behavior defined by the experimental procedure versus engaging in some other behavior, whatever that may be.

According to Herrnstein (1970), choice between two alternatives is predicted by the "matching law" (de Villiers, 1977; Herrnstein, 1961; Nevin, 1984): response proportions match reinforcer proportions. Following the matching law, the choice between a single experimenter-

This research was supported by Grant T82/205 from the University Grants Committee. An earlier version was presented to the Operant Symposium at the New Zealand Psychological Society Conference, 1983. Reprint requests should be addressed to K. G. White, Department of Psychology, University of Otago, P. O. Box 56, Dunedin, New Zealand. defined operant response, $B$, and some other behavior, $B_{\mathrm{o}}$, is given by

$$
B /\left(B+B_{0}\right)=R /\left(R+R_{0}\right),
$$

where $R$ is the rate of reinforcers obtained by operant responses and $R_{\mathrm{o}}$ is the rate of extraneous reinforcers produced by other behavior.

Herrnstein $(1970,1974)$ assumed that when $B$ and $B_{0}$ are measured in the same units (e.g., responses per minute, or units of time), the sum $\left(B+B_{0}\right)$ necessarily exhausts all possible behavior in a situation. In particular, if the time in which $B$ and $B_{0}$ can occur is held constant, such as the duration of an experimental session, the sum $\left(B+B_{\mathrm{o}}\right)$ must also remain constant. A constant $k$ can therefore be substituted for the sum $\left(B+B_{0}\right)$ in Equation 1. The constant $k$ represents total behavior and is measured in the same units as $B$ (Herrnstein, 1979). Rearrangement of the resulting modification to Equation 1 gives a new equation (called "Herrnstein's equation'):

$$
B=k \cdot \mathrm{R} /\left(R+R_{\mathrm{o}}\right) .
$$

Equation 2 predicts absolute response rate, $B$, in terms of reinforcers earned by $B$ relative to reinforcers obtained from all possible sources (the reinforcement context). In terms of Herrnstein's theoretical analysis, $k$ represents to- 
tal behavior that occurs in a given period of time. If there is no reinforcement for "other" behavior, $B=k$. That is, $k$ also gives a measure of the maximum possible rate at which $B$ could occur. The constant $R_{\mathrm{o}}$ is measured in the same units as $\boldsymbol{R}$ (e.g., reinforcers per hour). Equation 2 defines a rectangular hyperbola with an asymptote at $B=k$ and with a rate of increase in $B$ with increasing $R$ given by $R_{\mathrm{o}}$. Changes in reinforcer parameters, such as reinforcer magnitude or quality, should affect $R_{\mathrm{o}}$ but not $k$, whereas changes in response parameters, such as topography or response force, should affect $k$ but not $R_{\mathrm{o}}$ (Herrnstein, 1974).

De Villiers and Herrnstein (1976) reviewed a large number of studies in which the strength of a single response varied with relative reinforcer frequency. As a general rule, fits of Equation 2 to the data from these studies were satisfactory. Satisfactory fits of an equation to data do not, however, provide an unequivocal test of the equation. Stronger tests come from studies in which response or reinforcer parameters are varied in such a way as to test predictions about their effects on the values of the constants $k$ and $\boldsymbol{R}_{\mathrm{o}}$. For example, Bradshaw, Szabadi, and Ruddle (1983) varied response force for a series of variable-interval (VI) reinforcement schedules and found lower values of $k$ for greater force requirements while $R_{\mathrm{o}}$ was unaffected, consistent with Herrnstein's (1974) interpretation of Equation 2. Similarly, McSweeney (1978) reported lower values of $k$ for treadle pressing than for keypecking with no change in the estimate for $R_{\mathrm{o}}$.

When reinforcer parameters are varied, $R_{\mathrm{o}}$ should be affected, but $k$ should not. Bradshaw, Szabadi, and Bevan (1978) reinforced rats' leverpress responses with sucrose according to several VI schedules in different conditions. As in other studies, response rate increased hyperbolically with reinforcement rate according to Equation 2. Values of $R_{\mathrm{o}}$ were lower for a strong sucrose concentration than for a weaker sucrose concentration, as expected from Herrnstein's interpretation of $\boldsymbol{R}_{\mathrm{o}}$. In other studies, Bradshaw, Szabadi, Ruddle, and Pears (1983) and Snyderman (1983) reported lower values of $R_{\mathrm{o}}$ for higher levels of food deprivation in rats, again consistent with Equation 2. More recently, McDowell and Wood (1984) varied the magnitude of reinforcers earned by humans. Response functions were adequately fitted by Equation 2, but our reanalysis indicated that $R_{\mathrm{o}}$ varied independently of reinforcer magnitude. Values of $k$ tended to vary directly with reinforcer magnitude, although they should have remained constant.

Perhaps the strongest test of Herrnstein's equation would be to vary directly the rate of extraneous reinforcement, $R_{\mathrm{o}}$. Unfortunately, such an experiment is impossible because $R_{\mathrm{o}}$ is a theoretical quantity that is unobservable. An approximation to such a test, however, would involve providing a reinforcement source additional to whatever extraneous reinforcement was already available. Although variation in such factors as deprivation level or reinforcer magnitude can only allow inferences about the resulting levels of extraneous reinforcement, the explicit programming of reinforcement additional to extraneous reinforcement allows the minimum levels of $R_{0}$ to be specified.

In the present experiment, the absolute rate of rats' responses on the right lever of a two-lever chamber was recorded under several conditions in which the VI reinforcement schedule was varied. An additional source of reinforcement was programmed in each session, namely reinforcers for responses on the left lever. Reinforcers for left- and right-lever responding were arranged according to concurrent VI VI schedules. Right-lever response rates, $B_{R}$, could therefore be predicted by reinforcers on the right, $\boldsymbol{R}_{\mathbf{R}}$, reinforcers on the left, $\boldsymbol{R}_{\mathrm{L}}$, and reinforcers for other behavior, $R_{0}^{\prime}$, according to Equation 3:

$$
B_{\mathbf{R}}=k \cdot R_{\mathbf{R}} /\left(\boldsymbol{R}_{\mathbf{R}}+\boldsymbol{R}_{\mathbf{L}}+\boldsymbol{R}_{\mathbf{o}}^{\prime}\right) \text {. }
$$

The sum $\left(R_{\mathrm{L}}+R_{0}^{\prime}\right)$ in Equation 3 is equal to $R_{\mathrm{o}}$ in Equation 2. Fits of Equation 2 to data for right-lever responding yield estimates of $k$ and $R_{\mathrm{o}}$. According to Herrnstein's (1974) interpretation of $R_{0}$, we expected that the values of $R_{\mathrm{o}}$ required to fit the data adequately should be at least as large as the rate of reinforcers obtained by left-lever responses, $R_{\mathrm{L}}$.

For each of three groups of hooded rats in the present experiment, the value of $R_{L}$ was held constant, but at different levels for the different groups. In Group $R_{\mathrm{L}}=68$, reinforcers were obtained by left responses at an average rate of $68 / \mathrm{h}$. In the $R_{\mathrm{L}}=26$ and $R_{\mathrm{L}}=9$ groups, left reinforcers were obtained at rates averaging $26 / \mathrm{h}$ and $9 / \mathrm{h}$, respectively. Thus there were groups in which reinforcers were arranged for "other" behavior at high, medium, and low rates. According to Herrnstein's (1974) interpretation of $R_{\mathrm{o}}$, the values for $R_{\mathrm{o}}$ found by fitting Equation 2 to the data should be high, medium, and low, respectively, for the groups with high, medium, and low rates of $R_{\mathrm{L}}$. Furthermore, the values of $R_{\mathrm{o}}$ estimated from the fitted functions should be at least as large as the values of $R_{\mathrm{L}}$ obtained.

By varying $R_{\mathrm{L}}$ over different levels for the three groups, we hoped to discover whether the fitted parameter values corresponded to the minimal levels of extraneous reinforcers actually obtained.

\section{METHOD}

\section{Subjects}

The subjects were 24 female hooded rats maintained at $80 \% \pm 5 \%$ of their free-feeding weights. The rats were about 4 months old at the beginning of the experiment. Water was always available in the living cages, and supplementary feeding ensured maintenance of the prescribed body weights.

\section{Apparatus}

Twelve identical experimental chambers, $30 \times 25 \times 28 \mathrm{~cm}$ high, contained two response levers. The levers were mounted in one wall $10 \mathrm{~cm}$ from the grid floor and $8 \mathrm{~cm}$ on either side of center. A red lamp located above each lever was illuminated throughout the experimental sessions. Feedback was provided by each response's producing a .05-sec offset of the lamp above the associated lever. Each lever could be operated by a force of $.1 \mathrm{~N}$. 
A central dipper cup at floor level could deliver $.01 \mathrm{cc}$ of sweetened condensed milk diluted with an equal quantity of water. White noise presented through a speaker in each chamber at about $80 \mathrm{~dB}$ SPL served to mask extraneous sounds. Experimental events in each chamber were controlled and recorded by microcomputer control systems supplied by Micro Interfaces Ltd.

\section{Procedure}

Throughout the experiment, each daily session lasted for $30 \mathrm{~min}$. Individual rats always worked in the same chamber and 4 rats from each group of 8 worked in four chambers at the same time. The first 22 sessions were devoted to preliminary training. In Sessions 1 and 2 , there were 60 presentations of condensed milk at 30-sec intervals, independently of responding, in order to establish drinking following each dipper operation. Over Sessions 3 to 12, rightlever presses were established in an automaintenance procedure or by reinforcing successive approximations to right-lever responding. In Sessions 13-18, right responses were reinforced at intervals that increased from 10 to $40 \mathrm{sec}$ over sessions (VI $10 \mathrm{sec}$, VI $20 \mathrm{sec}$, VI $40 \mathrm{sec}$ ). In Sessions 19-22, responses on both left and right levers were reinforced according to the concurrent VI VI schedule described below. For Rats R1 to R8, the schedule was Conc VI 40 VI 40; for Rats R9 to R16, it was Conc VI 120 VI 120; and for Rats R17 to R24 it was Conc VI 300 VI 300.

In Sessions 23-83, responses on left and right levers were reinforced according to nonindependent concurrent VI VI schedules arranged following the method of Stubbs and Pliskoff (1969). With their method, the timing of the VI schedule on one side stops when a reinforcer is set up on the other side. Timing of both schedules continues only when the reinforcer set up by one has been obtained. This method ensures that the relative frequencies of obtained reinforcers correspond to the relative frequencies of programmed reinforcers. The VI schedules comprised 12 different intervals generated by a constant-probability progression (Fleshler \& Hoffman, 1962). The procedure included a $1-\mathrm{sec}$ changeover delay according to which a reinforcer could not be delivered for a response that occurred within $1 \mathrm{sec}$ of the first response made on a lever since changing over from the other lever.

For each rat, left and right responses were reinforced according to concurrent VI VI schedules in five conditions, which differed in terms of the VI schedule in effect for right-lever responses. The values of the right schedules were VI $40 \mathrm{sec}$, VI $80 \mathrm{sec}$, VI $120 \mathrm{sec}$, VI $160 \mathrm{sec}$, and VI $300 \mathrm{sec}$. For each group, the left schedule was held constant across all five right-schedule conditions. These were VI $40 \mathrm{sec}$ for Rats R1-R8 (Group $R_{\mathrm{L}}=68$ ), VI $120 \mathrm{sec}$ for Rats R9-R16 (Group $R_{\mathrm{L}}=26$ ), and VI $300 \mathrm{sec}$ for Rats R17-R24 (Group $R_{\mathrm{L}}=9$ ). Each condition was conducted for 12 sessions. The orders in which the conditions were conducted for each group were chosen so that right VI schedules alternated between high and low values, beginning with a nondifferential reinforcement condition (i.e., $R_{\mathrm{R}}=\boldsymbol{R}_{\mathrm{L}}$ ). In order of conduct, the right VI schedule values were $40,300,80,160,120$, for Rats R1-R8, 120, 40, 300, 80, 160 for Rats R9-R16, and 300, 80, 160, 120, 40 for Rats R17-R24.

\section{RESULTS}

Response and reinforcer frequencies summed over the last five sessions per condition for individual rats were converted to rates (responses per minute and reinforcers per hour) by dividing frequencies by total session duration. Mean rates of responding on the right, averaged over individuals within each group, are shown in Figure 1 as a function of mean reinforcers per hour obtained by right responses. The group designations $\left(R_{\mathrm{L}}=68, R_{\mathrm{L}}=26\right.$, $R_{\mathrm{L}}=9$ ) refer to mean reinforcers per hour obtained by left
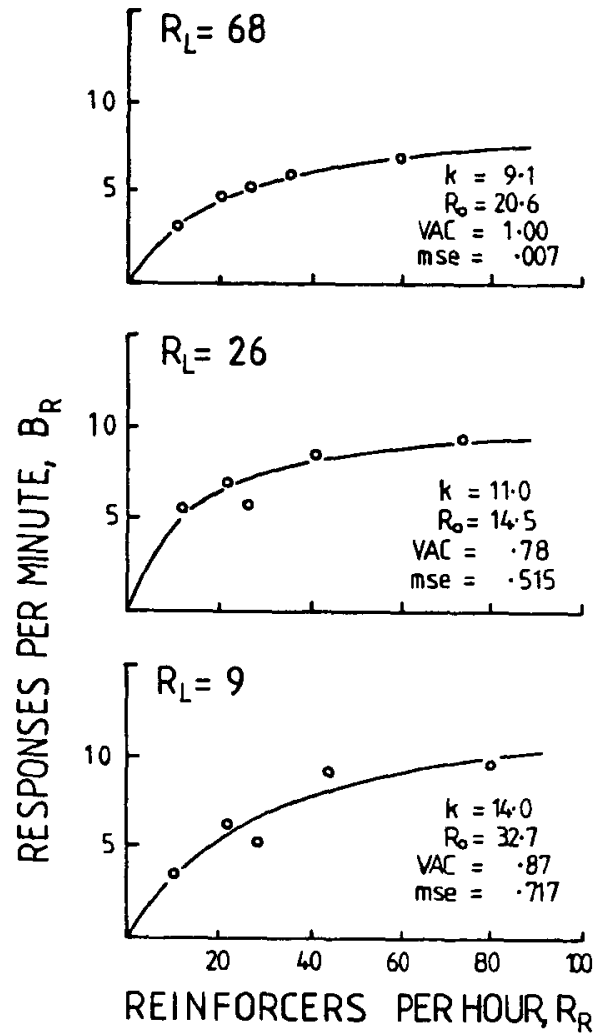

Figure 1. Rates of response on the right lever (responses per minute) as a function of reinforcers per hour on the right, averaged over individual rats in groups in which obtained left reinforcers averaged 68, 26, or 9 per hour. Estimates of $k$ and $R_{0}$ parameters for hyperbolas (smooth curves) best fitting mean response rates are given, along with the variance accounted for by the best-fitting hyperbolas (VAC) and the mean squared error (mse).

responses and averaged over individuals within each group (also see Table 1). Analysis of variance confirmed that mean rates of right responses increased systematically with increasing rate of reinforcers for right responses $[F(4,84)$ $=74.4, p<.0011$ and overall response rates differed between the three groups $[F(2,21)=5.8, p<.01]$. There was a significant interaction between groups and reinforcement condition $[F(8,84)=4.9, p<.001]$, suggesting that the groups differed in the extent to which right response rates increased with increasing rates of reinforcers for right responses.

The curres shown in Figure 1 are rectangular hyperbolas fitted to the data $\left(\boldsymbol{B}_{\mathrm{R}}\right)$ using a nonlinear least squares method (Wetherington \& Lucas, 1980; also see Cliffe, 1983). The functions are described by Equation 2 . Values of the parameters $k$ and $R_{\mathrm{o}}$ for the best fitting functions are given in Figure 1. Wilkinson's fitting procedure (McDowell, 1981) gave very similar parameter estimates. Also shown are estimates of variance in the data accounted for by the predictions (VAC) and the mean squared error (mse), both of which indicate that the fits of Equation 2 to the data were satisfactory.

Differences between the values of $k$ and $R_{\mathrm{o}}$ for hyperbolas best fitting the group mean rates in Figure 1 were 
consistent with the data for individual subjects. Figure 2 shows rates of right responses as a function of rates of obtained reinforcers on the right for individual rats in the three groups. Rectangular hyperbolas were fitted to response rates for individual rats using the nonlinear least squares method described by Wetherington and Lucas (1980). The means and medians of the $k$ and $R_{\mathrm{o}}$ parameters for individual functions (Figure 2) were close to the $k$ and $R_{\mathrm{o}}$ values for hyperbolas fitted to the group mean data (Figure 1). According to a Kruskal-Wallis nonparametric analysis of variance, the mean values of $k$ differed over the three groups $(H=7.22, p<.05)$ and the mean values for $R_{\mathrm{o}}$ (Table 1) also differed $(H=6.98$, $p<.05)$. $R_{\mathrm{o}}$ values for the $R_{\mathrm{L}}=68$ group were overall smaller than those for the $R_{\mathrm{L}}=9$ group (Mann-Whitney $U=15, p<.05$ ), but there was considerable overlap for the $R_{\mathrm{o}}$ values for the $R_{\mathrm{L}}=68$ and $R_{\mathrm{L}}=26$ groups

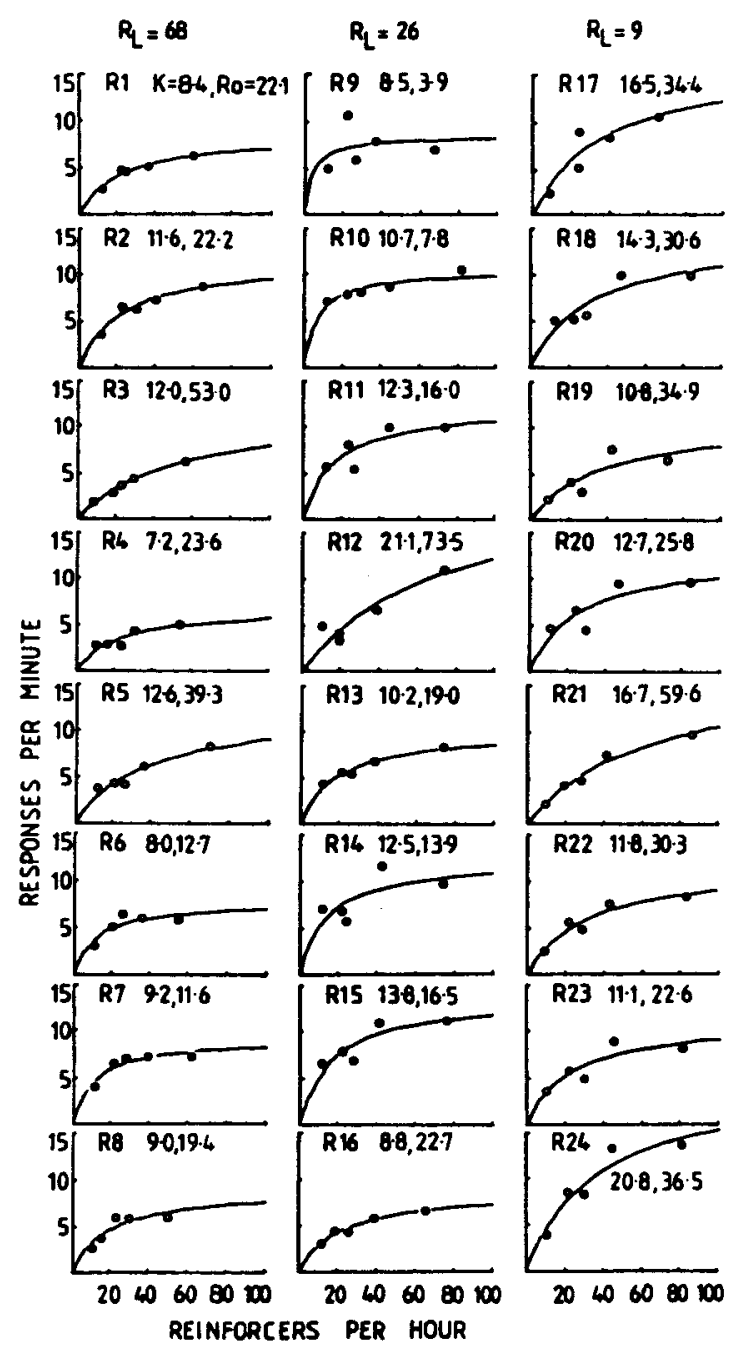

Figure 2. Responses per minute on the right lever as a function of reinforcers per hour obtained on the right by individual rats in groups in which obtained left reinforcers averaged 68, 26, or 9 per hour. Estimates of $k$ and $R_{0}$ for best-fitting rectangular hyperbolas are shown.
Table 1

Mean Reinforcers per Hour Obtained by Left Responses $\left(R_{L}\right)$ and Estimates of $\boldsymbol{R}_{\mathrm{o}}$ in Reinforcers per Hour for Each Rat

\begin{tabular}{|c|c|c|c|c|c|c|c|c|}
\hline \multicolumn{3}{|c|}{$R_{\mathrm{L}}=68$} & \multicolumn{3}{|c|}{$R_{\mathrm{L}}=26$} & \multicolumn{3}{|c|}{$R_{\mathrm{L}}=9$} \\
\hline Subject & $\boldsymbol{R}_{\mathrm{L}}$ & $R_{0}$ & Subject & $R_{\mathrm{L}}$ & $R_{\mathrm{o}}$ & Subject & $R_{L}$ & $R_{\mathrm{o}}$ \\
\hline R1 & 71.4 & 22.1 & R9 & 25.4 & 3.9 & R17 & 8.2 & 34.4 \\
\hline $\mathbf{R} 2$ & 76.6 & 22. & R10 & 28.7 & 7.8 & R18 & 10.4 & 30.6 \\
\hline R3 & 60.8 & 53.0 & $\mathbf{R} 11$ & 27.3 & 16.0 & R19 & 7.9 & 34.9 \\
\hline R4 & 61.0 & 23.6 & R12 & 23.4 & 73.5 & R20 & 10.6 & 25.8 \\
\hline R5 & 72.7 & 39.3 & R13 & 27.0 & 19.0 & $\mathbf{R 2 1}$ & 9.6 & 59.6 \\
\hline R6 & 69.0 & 12.7 & R14 & 27.0 & 13.9 & R22 & 8.9 & 30.3 \\
\hline R7 & 74.2 & 11.6 & R15 & 28.1 & 16.5 & R23 & 9.3 & 22.6 \\
\hline R8 & 59.4 & 19.4 & R16 & 23.8 & 22.7 & R24 & 9.8 & 36.5 \\
\hline
\end{tabular}

( $U=21, p>.05)$. The result that $R_{\circ}$ values differed over groups is consistent with the significant interaction between group and reinforcement rate in the analysis of variance on right-response rates.

To summarize the results in Figures 1 and 2, the three groups differed in terms of the parameters for Herrnstein's equation, with the group in which $\boldsymbol{R}_{\mathrm{L}}$ was highest having smaller values of both $R_{\mathrm{o}}$ and $k$ than did the group in which $R_{\mathrm{L}}$ was lowest.

Did the values of $R_{\mathrm{o}}$ estimated by fitting Equation 2 to right-response rates exceed the values of $R_{\mathrm{L}}$ actually obtained by left responses? Table 1 gives the comparison between obtained $R_{\mathrm{L}}$ values and the estimate of $R_{\mathrm{o}}$ for individuals in each group. For each rat in the $R_{\mathrm{L}}=68$ group, estimated $R_{\mathrm{o}}$ was smaller than obtained $R_{\mathrm{L}}$ (sign test, $p<.01$ ). For each rat except $\mathrm{R} 12$ in the $R_{\mathrm{L}}=26$ group, estimated $R_{\mathrm{o}}$ was smaller than obtained $R_{\mathrm{L}}$ (sign test, $p<.05$ ). But for each rat in the $R_{\mathrm{L}}=9$ group, $\boldsymbol{R}_{\mathrm{o}}$ was greater than $R_{\mathrm{L}}(p<.01)$. Only for the $R_{\mathrm{L}}=9$ group, therefore, was $R_{\mathrm{o}}$ greater than $R_{\mathrm{L}}$, although the estimate of $R_{\mathrm{o}}$ is meant to include reinforcers from all sources other than $R_{\mathrm{R}}$ (i.e., $R_{\mathrm{o}}=R_{\mathrm{L}}+R_{\mathrm{o}}^{\prime}$ ).

\section{Undermatching of Response Ratios}

Herrnstein's (1970) argument is premised on the assumption that response proportions directly match reinforcer proportions as described in Equation 1. Equation 1 can be expressed in ratios rather than proportions. For the choice between left and right responses in the present experiment, the matching law predicts that:

$$
B_{\mathbf{R}} / B_{\mathbf{L}}=R_{\mathbf{R}} / R_{\mathbf{L}} \text {. }
$$

The extant evidence suggests, however, that response ratios "undermatch" reinforcer ratios according to the following power function (Baum, 1974; Wearden, 1983; Wearden \& Burgess, 1982):

$$
B_{\mathrm{R}} / B_{\mathrm{L}}=c\left(R_{\mathrm{R}} / R_{\mathrm{L}}\right)^{a} .
$$

In Equation 4, the exponent $a$ describes the sensitivity of response ratios to changes in reinforcer ratios, and $c$ is a constant or inherent bias toward left or right responses. Herrnstein's (1970) "matching law" is a special case of Equation 4 in that when $a=1$ and $c=1$, Equation 4 is equivalent to Equation 1. Undermatching occurs when sensitivity $(a)$ is less than 1.0. The logarithmic transfor- 
mation of Equation 4 is a straight line with a slope of $a$ and intercept $\log c$.

To determine whether undermatching occurred in the present data, logarithms (base 10) or ratios of right-toleft response rates were expressed as a function of logarithms (base 10) of ratios of right-to-left reinforcer rates. Straight lines were fitted to the $\log$ ratios by the method of least squares. Table 2 gives the values of $a$, $\log c$, and the standard error of the estimate (se) for the straight lines best fitting the log ratios for each rat. In all cases, the fits were excellent, as indicated by the small standard errors of the estimate. Therefore the data were fitted by Equation 4 very well. For the $R_{\mathrm{L}}=68, R_{\mathrm{L}}=26$, and $R_{\mathrm{L}}=9$ groups, respectively, the mean values of $a$ were $.59, .49$, and .41 and the mean values of $\log c$ were 0 , .10 , and .14. Kruskal-Wallis nonparametric analyses of variance indicated that the mean parameter estimates differed across the three groups for both $a(H=9.22$, $p<.05)$ and $\log c(H=7.25, p<.05)$.

The results of linear regression analyses for individual subjects were consistent with similar analyses conducted for response and reinforcer rates averaged over individuals in each group. Log responses and reinforcer ratios for the groups are shown in Figure 3.

It may be noted that the data points in Figure 3 are displaced to the left and right of the origin for the $R_{\mathrm{L}}=68$ and $R_{\mathrm{L}}=9$ groups, respectively, because the denominator of the reinforcer ratios was always high (68) or low (9). The values of $a$ and $\log c$ for straight lines fitted to the log response ratios in Figure 3 were very close to the mean $a$ and $\log c$ values obtained from individual regression analyses. In all cases, there was undermatching. The

Table 2

Parameter Estimates for Sensitivity $(a)$ and Bias $(\log c)$ and Standard Errors of the Estimate (se) for Fits of Equation 3 to Log Response Ratios for Each Rat

\begin{tabular}{lllll}
\hline Group & Subject & $a$ & $\log c$ & se \\
\hline$R_{\mathrm{L}}=68$ & R1 & .58 & -.03 & .04 \\
& R2 & .69 & -.01 & .08 \\
& R3 & .57 & .05 & .01 \\
& R4 & .57 & -.02 & .08 \\
& R5 & .55 & -.03 & .06 \\
& R6 & .64 & -.08 & .06 \\
& R7 & .48 & -.01 & .07 \\
$R_{\mathrm{L}}=26$ & R8 & .61 & .17 & .06 \\
& R9 & .37 & .25 & .09 \\
& R10 & .33 & .02 & .02 \\
& R11 & .59 & .08 & .07 \\
& R12 & .55 & .05 & .05 \\
& R13 & .52 & .11 & .02 \\
& R14 & .35 & .27 & .08 \\
& R15 & .48 & .17 & .06 \\
$R_{\mathrm{L}=9}$ & R16 & .76 & -.15 & .03 \\
& R17 & .48 & .15 & .05 \\
& R18 & .38 & .12 & .07 \\
& R19 & .47 & .12 & .03 \\
& R20 & .41 & .15 & .07 \\
& R21 & .50 & .05 & .10 \\
& R22 & .40 & .13 & .09 \\
& R23 & .14 & .26 & .03 \\
& R24 & .48 & .10 & .10 \\
& & &
\end{tabular}

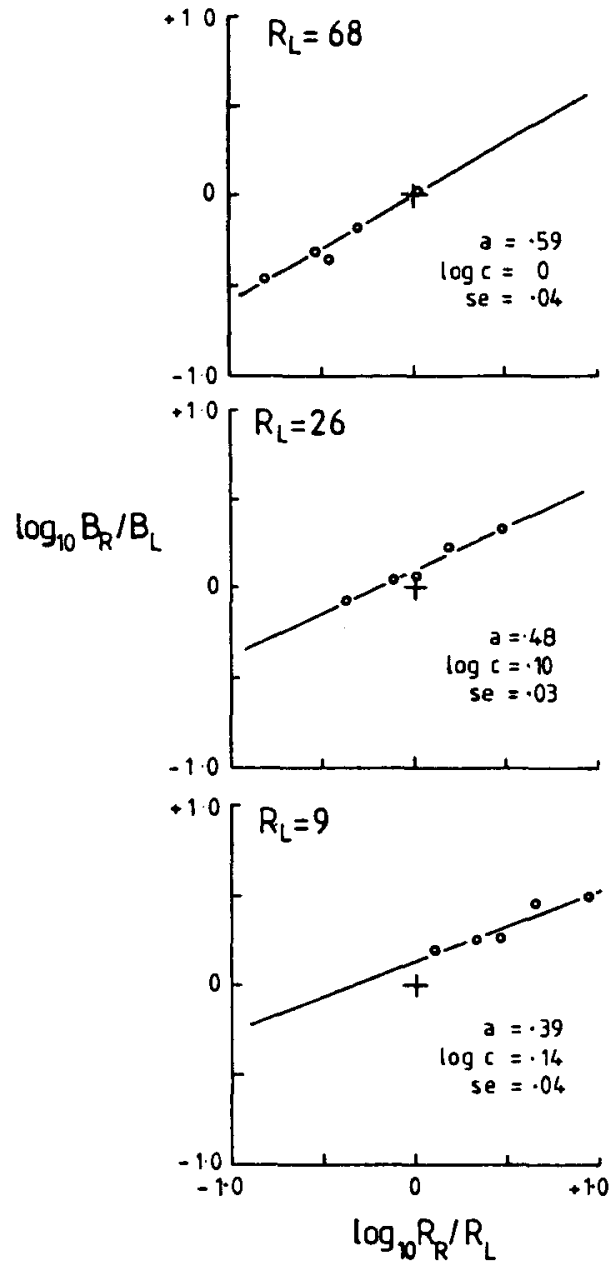

Figure 3. Logarithms (base 10) of ratios of right-to-left responses as a function of logarithms (base 10) of ratios of right-to-left reinforcers for the $R_{\mathrm{L}}=68, R_{\mathrm{L}}=26$, and $R_{\mathrm{L}}=9$ groups. The large cross is the origin for each function. Values for the slope $(a)$, intercept $(\log c$ ), and the standard error of the estimate (se) for the best-fitting straight lines are shown.

greatest sensitivity ( $a=.59$ ) was for the group in which reinforcer rates for left responses were high $\left(R_{\mathrm{L}}=68\right)$, and sensitivity was least $(a=.39$ ) for the group where $R_{\mathrm{L}}$ was low $\left(R_{\mathrm{L}}=9\right)$. Inherent bias, measured by the intercepts of the straight lines $(\log c)$, was also affected by the rate of reinforcers obtained by left responses. Smaller values of $\boldsymbol{R}_{\mathrm{L}}$ across the three groups resulted in overall stronger bias toward responding on the right.

In conclusion, there was clear evidence for undermatching in the relation between response and reinforcer ratios, and the extent of both undermatching and bias were affected by the rate of reinforcers obtained by left responses.

\section{DISCUSSION}

The response-reinforcer relations in the present experiment were adequately described by the hyperbolic func- 
tion proposed by Herrnstein (1970). In this respect, the data are consistent with those of many previous studies in which Herrnstein's equation provides a very good account of changes in absolute response rates as a function of reinforcer rates arranged by single VI schedules (Bradshaw, Ruddle, \& Szabadi, 1981; de Villiers \& Herrnstein, 1976) or by concurrent schedules (McSweeney, Melville, \& Whipple, 1983). The present data raise two problems for Herrnstein's $(1970,1974)$ interpretation of the $R_{\mathrm{o}}$ parameter, however. First, estimates of $R_{\mathrm{o}}$ for the three groups did not vary directly with the rate of additional reinforcers obtained by left responses $\left(R_{\mathrm{L}}\right)$. Second, for two of the groups, $R_{\mathrm{o}}$ estimates were smaller than the $R_{\mathrm{L}}$ rates actually obtained, whereas $R_{\mathrm{o}}$ estimates should have been greater because $R_{\mathrm{L}}$ is included in $\boldsymbol{R}_{\mathrm{o}}$. These problems can be resolved, however, if the undermatching and bias that were found in the present data are taken into account in revising Herrnstein's equation.

In previous studies with single VI schedules, $R_{\mathrm{o}}$ estimates for different levels of sucrose concentration (Bradshaw et al., 1978) and food deprivation (Bradshaw et al., 1983; Snyderman, 1983) concur with Herrnstein's interpretation in that smaller values of $R_{\mathrm{o}}$ are expected when programmed reinforcer value is high. Although such a conclusion has face validity, it is circumstantial because it requires the size of $R_{0}$ to be inferred from the values of programmed reinforcers. The conclusion is based on the implicit and probably wrong assumption that the total rate of reinforcers obtained from all sources is constant-it is feasible for obtained rates of programmed and extraneous reinforcers to be both high or both low. To test the assumption that $R_{\mathrm{o}}$ represents the rate of reinforcers obtained from extraneous sources, $R_{\mathrm{o}}$ must be manipulated in some measurable way.

Because it is impossible to measure $R_{\mathrm{o}}$ directly, the strategy of the present study was to add different levels of known reinforcers to extraneous reinforcers. That is, reinforcers other than those for right-lever responding included left reinforcers and extraneous reinforcers. The result did not agree with Herrnstein's $(1970,1974)$ interpretation of $R_{\mathrm{o}}$ : estimated values of $R_{\mathrm{o}}$ for Equation 2 were higher in the group in which added $R_{\mathrm{L}}$ was low than in the groups in which added $R_{\mathrm{L}}$ was high. It should be noted that the logic of this strategy for testing Herrnstein's equation relied on $R_{\mathrm{o}}^{\prime}$ (where $R_{\mathrm{o}}=R_{\mathrm{L}}+R_{\mathrm{o}}^{\prime}$ ) remaining constant across the three groups. It is conceivable that $R_{\mathrm{o}}^{\prime}$ changed over the three groups, in which case the direction of the difference between $R_{0}$ estimates for the different groups does not provide a strong test of Herrnstein's equation.

Nevertheless, the magnitude of $R_{0}$ estimates should have been at least as great as $R_{\mathrm{L}}$ values. For two of the three groups this was not the case. When $R_{\mathrm{L}}$ was subtracted from the $R_{\mathrm{o}}$ estimate to yield $R_{0}^{\prime}$, the many instances of negative values of $R_{0}^{\prime}$ clearly contradict Herrnstein's $(1970,1974)$ formulation. In a recent review of the applicability of Herrnstein's equation to concurrent schedules, McSweeney et al. (1983) noted a similar problem of negative values of $R_{\mathrm{o}}$ from their reanalyses of previous data. Formal problems for Herrnstein's formulation are created by negative values of $\boldsymbol{R}_{\mathrm{o}}$ :

If the absolute value of a negative $R_{0}$ is greater than the value of $R_{1}+R_{2}$, then Herrnstein's equation predicts negative response rates. If $R_{1}+R_{2}$ is slightly larger than the absolute value of a negative $R_{0}$, then response rates will be close to infinity and will decrease as $R_{1}+R_{2}$ increases. These predictions do not seem reasonable (McSweeney et al., 1983, p. 287).

Bradshaw (1977) has also reported a problem in the quantitative values for $R_{0}$. Bradshaw compared the response rates of rats under a range of VI schedules with a single lever with response rates under a (different) range of VI schedules, with responses on a second lever reinforced at a constant rate. Consistent with Herrnstein's interpretation of Equation 2, estimates of $R_{\mathrm{o}}$ were higher when the second lever was present. However, values for $R_{\mathrm{o}}$ with the second lever should have equaled the sum of obtained second-lever reinforcer rates and the estimate of $R_{\mathrm{o}}$ without the second lever, whereas they were considerably higher.

The problem of $R_{\mathrm{o}}$ values being wrongly estimated may be resolved by considering undermatching and bias. Ratios of response rates undermatched ratios of reinforcer rates, whereas Herrnstein's equation is based on the assumption that response ratios match reinforcer ratios. Hermstein's equation can be rewritten to take into account deviations from matching. That is, the essence of the formulation remains unaltered and the main premise is that choice between alternatives is described by Equation 4, the "generalized matching law." Equation 5 gives a "generalized" version of Herrnstein's equation as applied to the present procedure (cf. Davison \& Hunter, 1976; Wearden, 1981):

$$
B_{\mathrm{R}}=k R_{\mathrm{R}}^{a} /\left(R_{\mathrm{R}}^{a}+b R_{\mathrm{L}}^{a}+R_{\mathrm{o}}^{\prime}\right) .
$$

In Equation 5, the reinforcer rates are raised to the power $a$, describing the sensitivity of the choice between $B_{\mathrm{R}}$ and $B_{\mathrm{L}}$ in Equation 4 to the ratio of $R_{\mathrm{R}}$ and $R_{\mathrm{L}}$. The constant, $b$, is the inverse of the bias term $(c)$ in Equation 4 . The rate of reinforcers from extraneous sources is given by $R_{\mathbf{0}}^{\prime}$. Wearden (1981) has argued that small deviations from matching should make little difference to the extent that estimates of $k$ and $R_{\mathrm{o}}$ are wrongly estimated. Yet large deviations, as found in the present data (Figure 3) may be influential. [Parenthetically, although it is plausible that more extensive training (Todorov, Castro, Hanna, de Sa, \& Barreto, 1983) or a longer changeover delay may have resulted in less undermatching in the present data, there remain many conditions under which undermatching occurs (Taylor \& Davison, 1983) and hence would provide a problem for Equation 2.] We fitted Equation 5 to the group-mean response rates to take into account the undermatching and bias found for the functions relating left-to-right response ratios to reinforcer ratios (Figure 3 ). For the $R_{\mathrm{L}}=68$, 
$R_{\mathrm{L}}=26$, and $R_{\mathrm{L}}=9$ groups, respectively, estimates of the term $\left(b R_{\mathrm{L}}^{a}+R_{\mathrm{o}}^{\prime}\right)$ were 17,8 , and 87 . Subtracting values for $b R_{\mathbf{L}}^{a}$ from the latter estimates gave $R_{\circ}^{\prime}=5,14.2$, and 85.3 for the three groups. We conclude, therefore, that obtained rates of other reinforcers, $R_{\mathrm{o}}^{\prime}$, were different in the three groups, with highest rates of $R_{\mathrm{o}}^{\prime}$ in the group with the lowest rates of added left-lever lever reinforcers $\left(R_{\mathrm{L}}=9\right)$ and lowest $R_{\mathrm{o}}^{\prime}$ rates in the $R_{\mathrm{L}}=68$ group.

We also fitted Equation 5 to the data for individual subjects, using estimates of $a$ and $b$ from the regression analyses on log ratios (Table 2). For each subject except R9, estimates of $R_{\mathrm{o}}^{\prime}$ were positive, thus confirming the utility of Equation 5, whereas fits of Equation 2 yielded many negative values of $\boldsymbol{R}_{\mathrm{o}}$. It should be noted, however, that we found the procedure for fitting Equation 5 to the individual data unsatisfactory. The problem was that when reinforcer rates were raised to the power $a$, the range of $x$ values for the purpose of the fitting procedure was seriously attenuated, and consequently the fits may be unreliable, even if they did make sense. Further study of the generalized version of Herrnstein's equation given by Equation 5 will require manipulation of reinforcement rates over a much wider range than in the present study.

In Equation 3, $R_{\mathrm{o}}^{\prime}$ was assumed to remain constant over the three groups, but the present analysis shows that this assumption was probably wrong. Furthermore, taking undermatching and bias into account in Equation 5 yielded estimates of $R_{0}^{\prime}$ that were positive, were in a plausible range (cf. McSweeney et al., 1983), and were systematically related to the obtained $R_{\mathrm{L}}$ values. That is, the $R_{\mathrm{o}}^{\prime}$ values estimated by taking undermatching and bias into account were consistent with Herrnstein's interpretation. We therefore conclude that Herrnstein's (1970) fundamental notion, that response rates on single VI schedules can be predicted in terms of the choice between VI reinforcers and reinforcers obtained from extraneous sources, remains tenable. But the specific predictions about the effects of the reinforcement context are likely to be inaccurate unless we take into account the undermatching and bias that typically occur in the matching relation between response and reinforcer ratios.

\section{REFERENCES}

BAUM, W. M. (1974). On two types of deviation from the matching law: Bias and undermatching. Journal of the Experimental Analysis of Behavior, 22, 231-242.

Bradshaw, C. M. (1977). Suppression of response rates in variableinterval schedules by a concurrent schedule of reinforcement. British Journal of Psychology, 68, 473-480.

Bradshaw, C. M., Ruddle, H. V., Szabadi, E. (1981). Studies of concurrent performances in humans. In C. M. Bradshaw, E. Szabadi, \& C. F. Lowe (Eds.), Quantification of steady-state operant behaviour. Amsterdam: Elsevier/North-Holland Biomedical Press.

Bradshaw, C. M., Szabadi, E., \& Bevan, P. (1978). Relationship between response rate and reinforcement frequency in variable-interval schedules: The effect of the concentration of sucrose reinforcement. Journal of the Experimental Analysis of Behavior, 29, 447-452.

Bradshaw, C. M., Szabadi, E., \& Ruddle, H. V. (1983). Herm- stein's equation: Effect of response-force requirement on performance in variable-interval schedules. Behaviour Analysis Letters, 3, 93-100. Bradshaw, C. M., Szabadi, E., Ruddle, H. V., \& Pears, E. (1983). Herrnstein's equation: Effect of deprivation level on performance in variable-interval schedules. Behaviour Analysis Letters, 3, 267-273.

Cliffe, M. J. (1983). A Basic program for the non-linear least squares method of estimating the parameters of Herrnstein's hyperbola. Behavior Analysis Letters, 3, 353-357.

Davison, M. C., \& Hunter, I. W. (1976). Performance on variableinterval schedules arranged singly and concurrently. Journal of the Experimental Analysis of Behavior, 25, 335-345.

DE VILLIERS, P. (1977). Choice in concurrent schedules and a quantitative formulation of the law of effect. In W. K. Honig \& J. E. R. Staddon (Eds.), Handbook of operant behavior. Englewood Cliffs, NJ: Prentice-Hall.

de Villiers, P. A., \& Herrnstein, R. J. (1976). Toward a law of response strength. Psychological Bulletin, 83, 1131-1153

Fleshler, M., \& HofFMAN, H. S. (1962). A progression for generating variable-interval schedules. Journal of the Experimental Analysis of Behavior, 5, 529-530.

HERRNSTEIN, R. J. (1961). Relative and absolute strength of response as a function of frequency of reinforcement. Journal of the Experimental Analysis of Behavior, 4, 267-272.

HerRNSTEIN, R. J. (1970). On the law of effect. Journal of the Experimental Analysis of Behavior, 13, 243-266.

HERRNSTEIN, R. J. (1974). Formal properties of the matching law. Journal of the Experimental Analysis of Behavior, 21, 159-164.

Herrostein, R. J. (1979). Derivatives of matching. Psychological Review, 86, 486-495.

MCDowelL, J. J. (1981). Wilkinson's method of estimating the parameters of Herrnstein's hyperbola. Joumal of the Experimental Analysis of Behavior, 35, 413-414.

MCDOWELL, J. J., \& WoOD, H. M. (1984). Confirmation of linear system theory prediction: Changes in Herrnstein's $k$ as a function of changes in reinforcer magnitude. Journal of the Experimental Analysis of Behavior, 41, 183-192.

MCSWeEney, F. K. (1978). Prediction of concurrent keypeck treadlepress responding from simple schedule performance. Animal Learning \& Behavior, 6, 444-450.

MCSWeeney, F. K., Melville, C. L., \& Whipple, J. E. (1983). Hertnstein's equation for the rates of responding during concurrent schedules. Animal Learning \& Behavior, 11, 275-289.

Nevin, J. A. (1984). Quantitative analysis. Journal of the Experimental Analysis of Behavior, 42, 421-434.

SNYDERMAN, M. (1983). Body weight and response strength. Behaviour Analysis Letters, 3, 255-265.

StubBs, D. A., \& Pliskoff, S. S. (1969). Concurrent responding with fixed relative rate of reinforcement. Joumal of the Experimental Analysis of Behavior, 12, 887-895

TAYLOR, R., \& DAvison, M. (1983). Sensitivity to reinforcement in concurrent arithmetic and exponential schedules. Journal of the Experimental Analysis of Behavior, 39, 191-198.

Todorov, J. C., Castro, J. M. de O., Hanna, E. S., de Sa, M. C. N. B., \& BARRETo, M. DE Q. (1983). Choice, experience and the generalized matching law. Journal of the Experimental Analysis of Behavior, 40, 99-111.

WEARDEN, J. H. (1981). Bias and undermatching: Implications for Herrnstein's equation. Behaviour Analysis Letters, 1, 177-185.

WEARDEN, J. H. (1983). Undermatching and overmatching as deviations from the matching law. Journal of the Experimental Analysis of Behavior, 40, 332-340.

WEARDEN, J. H., BuRGESS, I. S. (1982). Matching since Baum (1979). Journal of the Experimental Analysis of Behavior, 38, 339-348.

Wetherington, C. L., \& LuCAs, T. R. (1980). A note on fitting Herrnstein's equation. Joumal of the Experimental Analysis of Behavior, 34, 199-206.

(Manuscript received April 24, 1985; revision accepted for publication June 2,1986 .) 